Check for updates

1 Eynsham, Oxfordshire, UK

2 , London, UK

Correspondence to: A Coulter

Cite this as: $B M J 2020 ; 370: m 3483$ http://dx.doi.org/10.1136/bmj.m3483 Published: 08 September 2020

\section{Care during covid-19 must be humane and person centred}

\author{
To achieve this, patient and family involvement must be strengthened
}

Angela Coulter, ${ }^{1,1}$ Tessa Richards ${ }^{2}$

The public swung solidly behind health and social care staff during the early phase of the covid-19 pandemic and applauded professionals' commitment, selflessness, and hard work. But patient organisations, including The BMJ's patient and public advisory panel, were dismayed to see how rapidly the hard won policies that embed the principle of patient and public involvement in healthcare decision making were swept away in the rush to respond to the crisis. ${ }^{1}$ Nearly nine months on, they are still being ignored or sidelined.

One important concern has been the blanket application of restrictive visiting rules that have prevented parents from staying with their children in hospital, barred fathers from labour wards, stopped families from visiting sick or dying relatives, and inhibited much needed comfort and support for those with physical or learning disabilities, mental health problems, or dementia. $^{2}$

The tragic consequences of these restrictions regularly feature in news stories and on social media, but there are other less obvious concerns too, including lack of shared decision making about treatment ${ }^{3}$ and end-of-life care, ${ }^{4}$ lack of focus on the specific needs of people with long term conditions, ${ }^{5}$ and failure to include lay people in decisions about reconfiguration of services and covid-19 research. ${ }^{6}$

The need for social distancing to prevent transmission of the virus is well understood, but a humane approach to visiting policies in hospitals and care homes need not be incompatible with an effective pandemic response. Family contact can, and in many settings is, being maintained through video conferencing, ${ }^{7}$ garden visits, ${ }^{8}$ and the opportunity to discuss concerns with staff, but a more flexible approach is required to allow family members to be with high risk patients, especially at the end of life. While some providers offer this, most do not. ${ }^{9} \mathrm{~A}$ Canadian group has called for named family members of high risk patients to be treated as essential partners in care, who could be exempted from visiting restrictions if they agree to abide by established safety protocols. $^{10}$

Although many patients have welcomed the rapid switch to virtual consultations and online health advice, the devil is in the detail. Patients need support and information to know what to expect and how best to prepare to ensure the quality of remote consultations, and health professionals need to learn how to conduct them well. ${ }^{11}$ Access to personal health records online will help empower patients, and now that multidisciplinary team meetings are conducted remotely, patients could be invited to join them.

\section{Emotional literacy}

Meanwhile, provider organisations need to acquire greater emotional literacy in how they deal with patients. Automated messages telling people not to bother the busy doctor are unhelpful and have surely contributed to the large reduction in uptake of non-covid care, storing up problems for the future. ${ }^{1213}$ Patient advocates have deplored the suggestion that health professionals do not need to collect patient feedback or respond promptly to complaints during the pandemic. ${ }^{14}$ Listening to patients and collecting, analysing, and using patient experience data are essential for maintaining and improving the quality and safety of care during and after the pandemic. ${ }^{15}$

Backing away from a person centred approach to treatment and care erodes trust and will cause more problems than it solves. Draconian implementation of policy responses to covid-19 have exacerbated health inequalities and ridden roughshod over human rights in some settings. ${ }^{16}$ Shared decision making is essential for good care and can be facilitated by providing patients and families with personalised information about covid-19 risks and decision aids to help them make informed choices. ${ }^{17}$ General practices are finding that care and support planning for those with long term conditions can be provided remotely, ${ }^{18}$ and hospital clinicians are using advance care plans to promote discussions with patients and families about resuscitation and palliative care. ${ }^{19}$

The willingness of patients and public to share responsibility for eliminating the virus is evident from the widespread acceptance of social distancing and mask wearing and the large numbers who volunteer to participate in research studies. Millions of people in the UK, US, and Sweden provide daily reports to the covid symptom study, the largest citizen science project ever mounted in health research. ${ }^{20}$ And the UK Health Research Authority's public involvement matching service has recruited 6000 lay volunteers keen to help shape covid-19 studies. ${ }^{21}$

The covid-19 pandemic is no reason to roll back the tide on person centred care. The arguments for it are sound and evidence based and, with effort and through co-design, can be achieved even without face-to-face contact. Ignoring the key role of families in the care of vulnerable people, failing to involve patients in decisions about their care, abandoning efforts to co-create services with those who will use them, and designing studies without consulting lay people is incredibly short sighted. It risks throwing away recent gains in higher quality, safer, more appropriate, effective, and efficient care. ${ }^{22}$

It could also undermine public solidarity at a point when healthcare providers need strong public 
support and understanding as they face the challenge of dealing with the fallout from delayed and disrupted care.

Competing interests: We have read and understood BMJ policy on declaration of interests and declare that $\mathrm{AC}$ is a member of The BM/S international patient and public advisory panel.

Provenance and peer review: Commissioned; not externally peer reviewed.

1 Richards T, Scowcroft HBMJ's international patient and public advisory panel. Patient and public involvement in covid-19 policy making. BMJ2020;370:m2575.

doi: 10.1136/bmj.m2575 pmid: 32611571

2 Frampton S, Agrawal S, Guastello S. Guidelines for family presence policies during the covid-19 pandemic. JAMA Health Forum 2020.[Epub ahead of print.] doi: 10.1001/jamahealthforum.2020.0807.

3 Simpson N, Milnes S, Steinfort D. Don't forget shared decision-making in the COVID-19 crisis. Intern Med J 2020;50:761-3. doi: 10.1111/imj.14862 pmid: 32537930

4 Rajagopal MR. To comfort always: are we ignoring this duty in covid protocols? Indian J Med Ethics 2020;5:189-91doi: 10.20529/IJME.2020.071 .

5 European Patients Forum. Now is the time to protect patients and safeguard access to care. 8 Apr/2020. https://www.eu-patient.eu/COVID-19/epf-covid-statements/epf-statement-on-thecovid-19-pandemic/

6 Hanley B, Tarpey M. Involving the public in Covid-19 research. 30 Apr 2020. https://www.hra.nhs.uk/about-us/news-updates/involving-public-covid-19-research-guest-blogbec-hanley-and-maryrose-tarpey/

7 Murray PD, Swanson JR. Visitation restrictions: is it right and how do we support families in the NICU during COVID-19?] Perinatol 2020 [Epub ahead of print].

doi: 10.1038/s41372-020-00781-1 pmid: 32772051

8 Coronavirus: Care home creates garden visits. BBC News 2020 Jun 18. https://www.bbc.co.uk/news/av/uk-53100600.

9 Munt C. Stop the harsh blanket ban on visitors in hospitals and care homes. BMJ Opinion, 3 Sep 2020. https://blogs.bmj.com/bmi/2020/09/03/carol-munt-stop-the-harsh-blanket-ban-on-visitorsin-hospitals-and-care-homes/

10 Drury J, Keresteci M, Snyman C. In this time of covid-19 there should be more, not less caregiver partnership. Medium, 7 May 2020. https://medium.com/in-this-time-of-covid-19-there-shouldbe-more-not/in-this-time-of-covid-19-there-should-be-more-not-less-caregiver-partnershipc1d595454da

11 Greenhalgh T, Wherton J, Shaw S, Morrison C. Video consultations for covid-19. BMJ 2020;368:m998. doi: 10.1136/bmj.m998 pmid: 32165352

12 Morris J. The alarming drop in referrals from GPs to hospital services since the Covid-19 outbreak. Nuffield Trust, 18 Jun 2020. https://www.nuffieldtrust.org.uk/resource/new-chart-of-the-weekthe-alarming-drop-in-referrals-from-gps-to-hospital-services-since-the-covid-19-outbreak

13 Maringe C, Spicer J, Morris M, etal. The impact of the COVID-19 pandemic on cancer deaths due to delays in diagnosis in England, UK: a national, population-based, modelling study. Lancet Oncol 2020;21:1023-34. doi: 10.1016/S1470-2045(20)30388-0 pmid: 32702310

14 Drinkwater J. Back to the future? Patient participation in general practice during covid-19. BMJ Opinion, 4 Jun 2020. https://blogs.bmj.com/bmj/2020/06/04/jessica-drinkwater-back-to-thefuture-patient-participation-in-general-practice-during-covid-19/

15 Independent Medicines and Medical Devices Safety Review. First do no harm. 2020. https://www.immdsreview.org.uk/Report.html

16 Resisting militarisation of the Covid-19 response, 2020. https://www.youtube.com/watch?v=wG9mG_EZU1U

17 National Hospice and Palliative Care Organisation. Coronavirus disease 2019 (covid-19) shared decision-making tool. 2020. https://www.nhpco.org/wp-content/uploads/COVID-19-Shared-Decision-Making-Tool.pdf

18 Year of Care Partnerships. Remote care and support planning. 2020. https://www.yearofcare.co.uk/remote-care-and-support-planning

19 Coleman JJ, Botkai A, Marson EJ, etal. Bringing into focus treatment limitation and DNACPR decisions: How COVID-19 has changed practice. Resuscitation 2020;155:172-9. doi: 10.1016/j.resuscitation.2020.08.006 pmid: 32827587

20 Drew DA, Nguyen LH, Steves C), etalCOPE Consortium. Rapid implementation of mobile technology for real-time epidemiology of COVID-19. Science 2020;368:1362-7. doi: 10.1126/science.abc0473 pmid: 32371477

21 Health Research Authority. Praise for new public involvement COVID-19 matching service. 2020 https://www.hra.nhs.uk/about-us/news-updates/praise-new-public-involvement-covid-19matching-service/

22 Coulter A. Engaging patients in healthcare. Open University Press, 2011.

This article is made freely available for use in accordance with BMJ's website terms and conditions for the duration of the covid-19 pandemic or until otherwise determined by BMJ. You may use, download and print the article for any lawful, non-commercial purpose (including text and data mining) provided that all copyright notices and trade marks are retained. 